\title{
Detailed quantitative description of fluvial reservoirs: A case study of L6-3 Layer of Sandgroup 6 in the second member of Shahejie Formation, Shengtuo Oilfield, China
}

\author{
Jingzhe $\mathrm{Li}^{1}, \mathrm{Ke} \mathrm{Yan}^{2}$, Huaiqiang $\mathrm{Ren}^{3}$, Zhifeng $\operatorname{Sun}^{1 \oplus *}$ \\ ${ }^{1}$ College of Electromechanics, Qingdao University of Science and Technology, Qingdao 266061, P. R. China \\ ${ }^{2}$ Shengli Oil Production Plant, Shengli Oilfield, Dongying 257051, P. R. China \\ ${ }^{3}$ School of Geosciences, China University of Petroleum (East China), Qingdao 266555, P. R. China
}

\section{Keywords:}

Quantitative reservoir description

geo-statistics

magnetic random walk model

fluvial facies

reservoir characterization

reservoir modelling

Cited as:

Li, J., Yan, K., Ren, H., Sun, Z. Detailed quantitative description of fluvial reservoirs: A case study of L6-3 Layer of Sandgroup 6 in the second member of Shahejie Formation, Shengtuo Oilfield, China. Advances in Geo-Energy Research, 2020, 4(1): 43-53, doi:

10.26804/ager.2020.01.05.

\begin{abstract}
:
The steady development of the oil field is facing severe challenges due to the problems of small-layer division, unclear genesis period and unclear river channel distribution in the 4-6 sand formation in the second district of Shengtuo Oilfield. Based on the processing and optimization of logging data, this paper firstly divided the isochronous strata and established the high-resolution isochronous stratigraphic framework. Using the geo-statistics method in the stratigraphic framework, the sand bodies in each small layer were divided according to the principle of equal time of fluvial facies. On this basis, the distribution pattern of the sand bodies in each stage was simulated by the magnetic random walk model. The magnetic random walk model has obtained robust simulation results, which is consistent with the anatomy of reservoir architectures by experienced geologists. The results also show that the number of channels in each small-layer is different, while the overall distribution of NE direction is reflected. At present, the model can well simulate the position of the main channel line, but it cannot reflect the variation of the river width. The method of quantitative fine description based on logging data has great potential application in fluvial reservoir, especially the magnetic random walk model that can reveal the distribution of sand body in every stage. At the same time, the model can also reflect certain randomness and facilitate the uncertainty analysis of geological factors.
\end{abstract}

\section{Introduction}

With the deepening of the development degree in old oilfields of eastern China, the once so called "main force" reservoirs are facing serious decline of production potential. Hence, the once "non-main force" sand bodies have gradually become a new kind of "main force". However, although the non-main force sandbodies are relatively rich in remaining oil due to the low degree of early exploitation, they are relatively weak in formation capacity and need more accurate water injection. This is bound to lead higher accuracy requirements to the reservoir characterization.

Shengtuo Oilfield is one of the earliest large-scale oil and gas fields developed in Bohai Bay Basin. After nearly 40 years of development, the main oil-producing layer has generally entered the stage of ultra-high water-bearing, and it is increasingly difficult to develop. The traditional reservoir characterization methods cannot reveal the complex structural characteristics of the fluvial facies reservoir, and the contact between the structural characteristics of the genetic sand body and the superimposed sand body needs to be deeply understood. The Sandgroup 4-6 of the second member of Shahejie Formation in District 2 is an important oil-bearing series in Shengtuo area, which is a typical distributary fluvial facies strata, with numerous periods, interlaced river network and rapid lateral change. From bottom to top, the Sandgroup 4-6 can be divided into 18 small layers, 7 of which are the so called "main force" layers, the remaining 11 are so-called "nonmain force" layers. At present, the main problems are that

${ }^{*}$ Corresponding author.

E-mail address: lijingzhe@qust.edu.cn (J. Li); yankeslof@sina.com (K. Yan); 19910025@upc.edu.cn (H. Ren);

zhifengsun879@gmail.com (Z.Sun)

2207-9963 (C) The Author(s) 2020.

Received February 14, 2020; revised February 24, 2020; accepted February 25, 2020; available online February $28,2020$. 


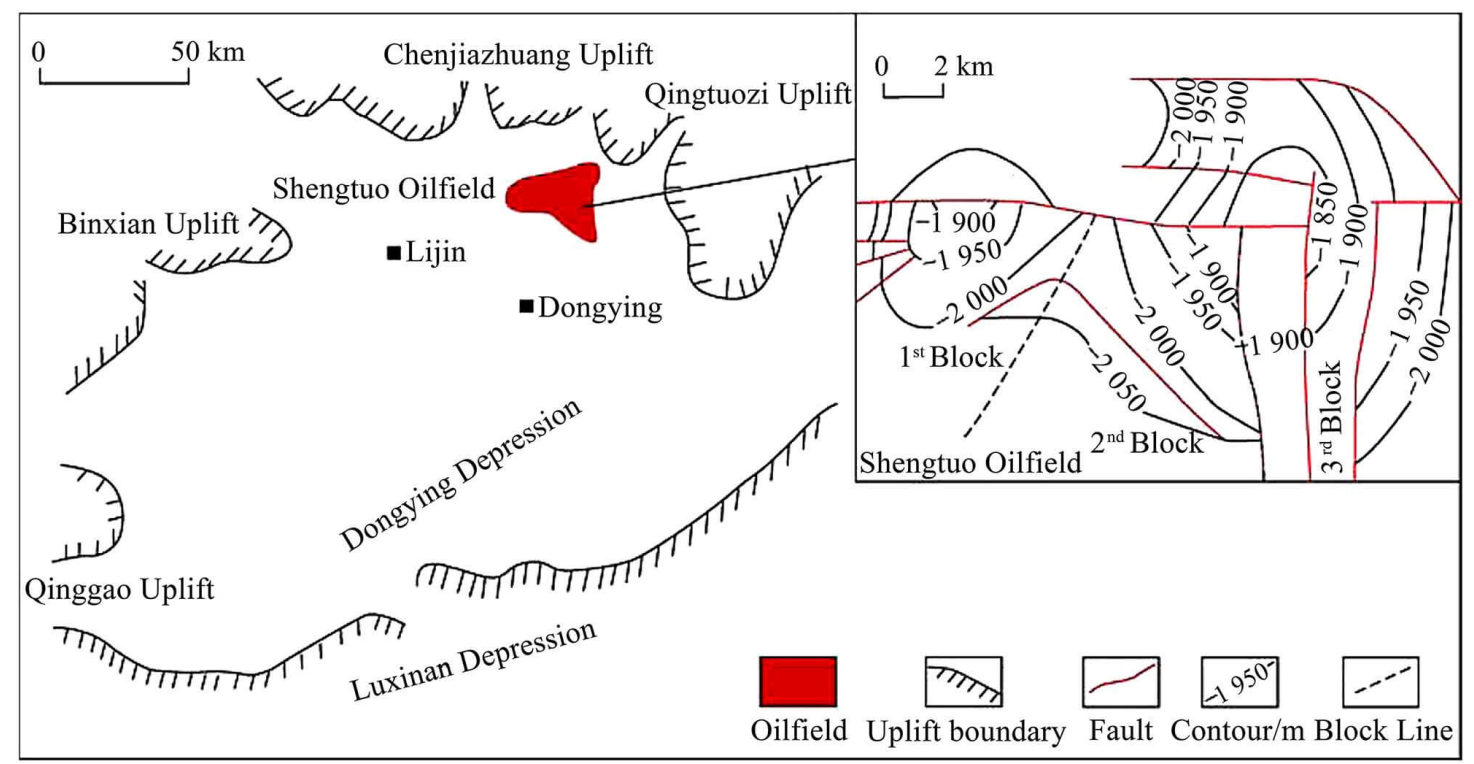

Fig. 1. Structural map of District 2 of Shengtuo Area (modified from Lin, 2007).

the division of small layers is not detailed enough, the period of sand body is not clear enough, and the space distribution is not clear enough. These sandbodies were usually described as "potato-shaped" distribution by traditional methods. However, it is obviously contrary to its origin, and it is more difficult to guide the development of water injection reasonably and effectively, which brings great inconvenience to the work of exploiting residual oil.

The modern reservoir architecture theory guided by outcrop and modern sedimentation can establish the river channel sand body geometry model, and can identify the isochronous nature of the sand body (Blacknell, 1982; Miall, 1988; Zhang et al., 1996; Yin et al., 1998; Xie et al., 2003; Willis, 2006; Nichols and Fisher, 2007; Wu et al., 2007; Yue et al., 2007; Donselaar and Overeem, 2008; Ma et al., 2008; Yu et al., 2008; Willis and Tang, 2010; Ghinassi, 2011; Kukulski et al., 2013; Colombera et al., 2017), which provides a new direction for the fine characterization of the river facies strata, and has achieved important results in the relevant areas (Jiao and Li, 1998; Liang et al., 2013; Li et al., 2015; Sun et al., 2018, 2020a, 2020b) . This is a big breakthrough in predicting the shape, extension characteristics and connectivity of the sand bodies with higher accuracy. However, it is a very timeconsuming and laborious work and poses great challenges to the experience of the practitioners.

Since the end of the 20th century, the application of various computer methods has profoundly changed human life. In the field of reservoir characterization and development, computer methods also bring great conveniences. Various geological modeling methods are incorporated into modern reservoir architecture theory (Wu and Li, 2007; Wang et al., 2009; Yin et al., 2011; Shi et al., 2011, 2012a, 2012b; Wang and Yin, 2017; Zheng et al., 2018), which not only quickly and conveniently replace a lot of tedious redundant work, but also upgrade the characterization from qualitative to quantitative, and enhance the maneuverability and evaluability.
In this paper, taking Sandgroup 4-6 of the second member of Shahejie Formation in District 2 as the study interval, and the "non-main force" L6-3 layer as the key case layer, this paper detailedly characterized the fluvial reservoir with several quantitative computer-aided methods, which is expected to provide a more robust and efficient geological basis for the next reservoir development adjustment and the implementation of exploiting measures.

\section{Geological settings}

Shengtuo Oilfield is located in the north steep slope belt of Dongying depression, stretching $20 \mathrm{~km}$ from west to east and $10 \mathrm{~km}$ from south to north. There are 12 main faults in shengtuo oilfield, which are divided into three oil zones, namely, District 1, District 2 and District 3. District 2, also called Sheng 2 District, is a very important oil-bearing district of Shengtuo Oilfield, located at the southwest wing of Shengtuo Area. District 2 is a right triangle shaped district, and is bounded by Fault 9 and 7 in the east and north respectively. Within the district, there are almost no internal faults, which makes it a structurally simple monoclinic reservoir (Fig. 1).

The second member of Shahejie Formation is a complete set of river-delta deposits with a thickness of about $670 \mathrm{~m}$. In District 2, the second member of Shahejie Formation is a set of delta plain deposits, mainly developing two sedimentary microfacies: distributary channel and interchannel bay. According to current understanding of the production side, the vertical stacking and lateral superposition of the channel sand body are complicated, and the sandbodies with narrow strip and so called isolated potato shapes are well developed in plane view. Sandgroup 4-6 can be are divided into 18 small layers. Among the 18 small layers, 11 ones are called non-main force layers (Fig. 2). The key case layer L6-3 is one of the 11 non-main force layers in this study. Previous studies have shown that the main-force layers are mainly of distributary channel deposits 


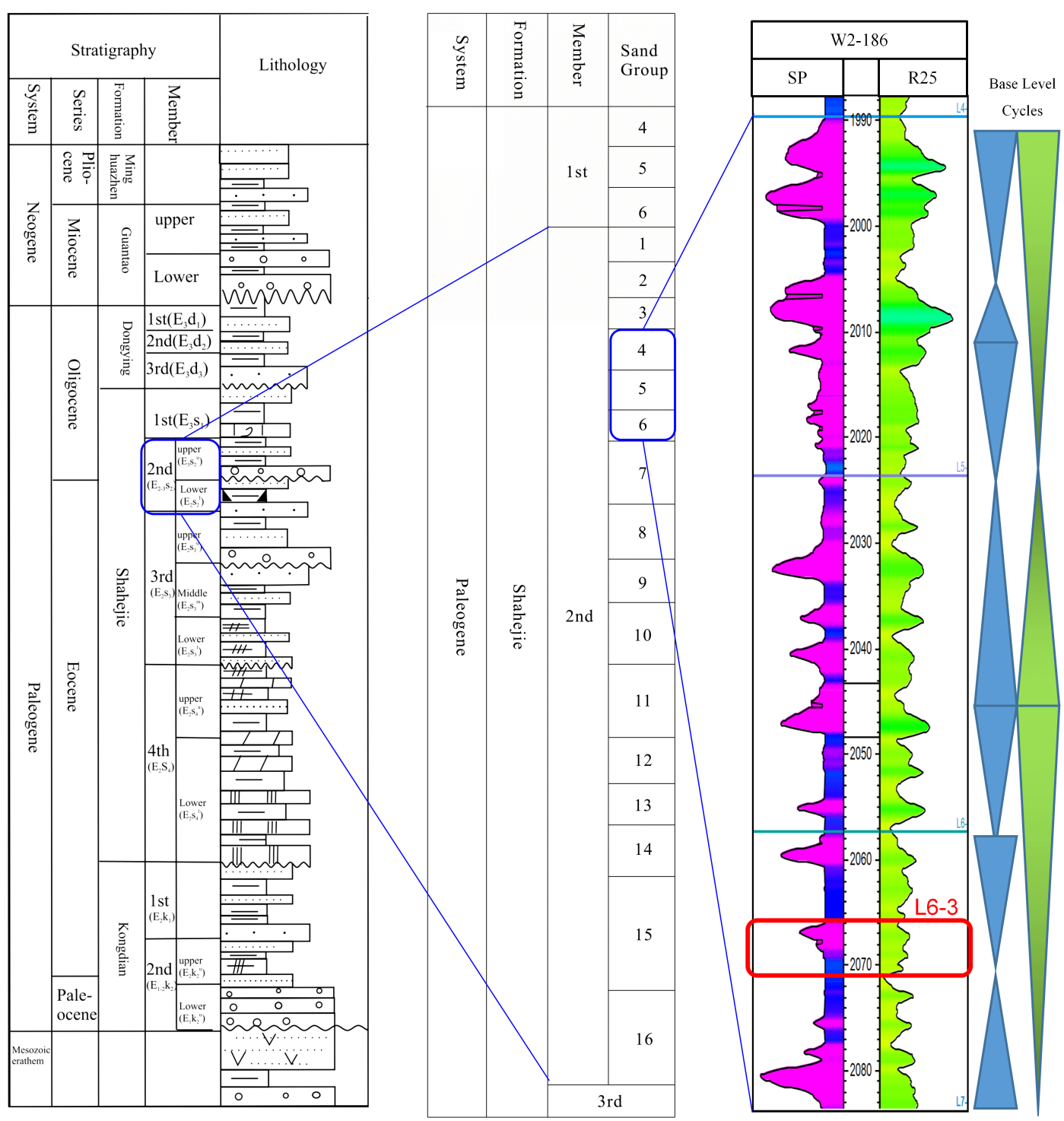

Fig. 2. Stratigraphy column of the target interval (modified from Lin, 2007; Yang et al., 2019; Zhu et al., 2020)

(i.e. sand-rich river channel microfacies), and non-main force layers are natural embankments and crevasse spray deposits (i.e. mud-rich non-channel microfacies).

\section{Materials and methods}

The data used in this study include well $\log$ data of nearly 500 wells, and relevant core logging and 3D seismic data. The overall technical route is shown in Fig. 3 (left). Firstly, the logging curve was processed and optimized, then the high-resolution isochronous stratigraphic framework was established by using the processed logging data. Then the sand body identification and splitting were carried out by using the sand body identification model. On this basis, the sand body data are statistically analyzed and their formation time stages were identified under the isochronous stratigraphic framework. Finally, random walk simulations were carried out to reveal the channel distribution of each stage based on a quasi-magnetic map derived from channel well observations and non-channel well observations.

The methods of SP curve processing and optimization, high-resolution isochronous stratigraphic framework establishment and quasi-magnetic random walk are detailedly clarified below.

\subsection{SP curve processing and optimization}

Well log curve processing and optimization are the basis of this study, and the main type of well log curve used in this study includes AC, SP, GR, COND and R25. Among them, the SP curve is closely related to stratigraphic correlation and sandbody identification. However, the ranges of the SP data of difference wells vary considerably due to many reasons. Hence, the shale baseline is very difficult to be identified. Hence, this study first carried out the SP curve processing and optimization.

The shale baseline is a prominent feature of the SP curve 

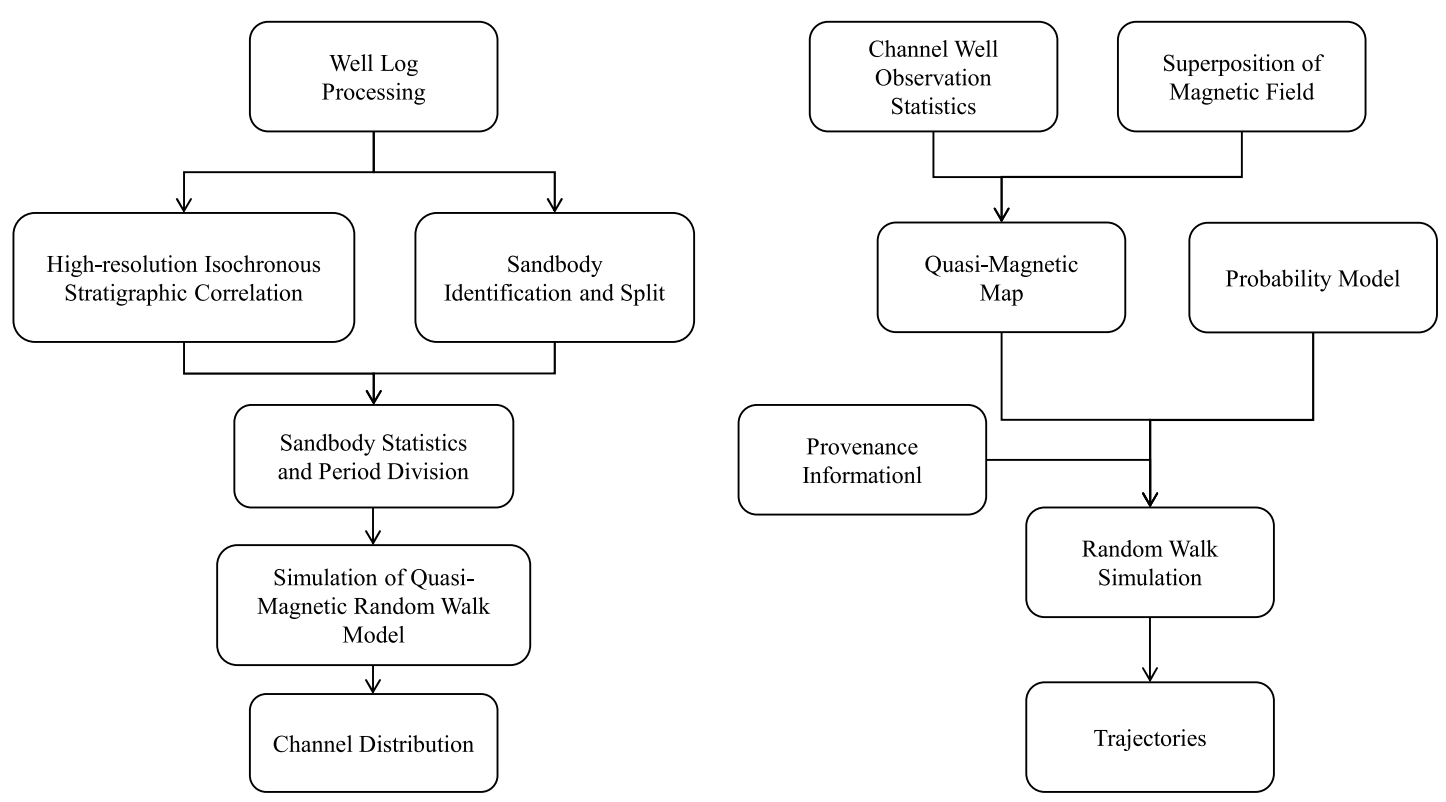

Fig. 3. Overall flowing chart of the quantitative reservoir characterization (left) and flowing chart of the quasi-magnetic random walk simulation (right).

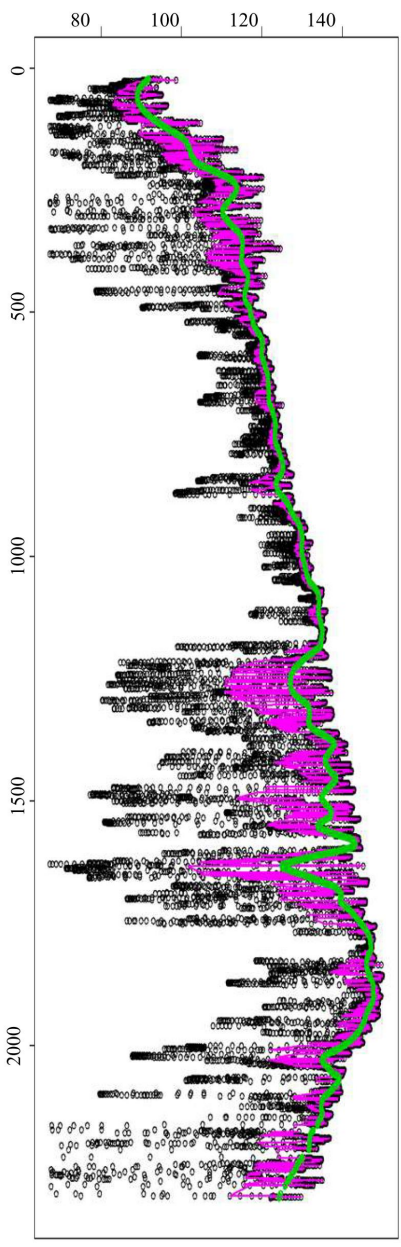

$\mathrm{ni}=1$

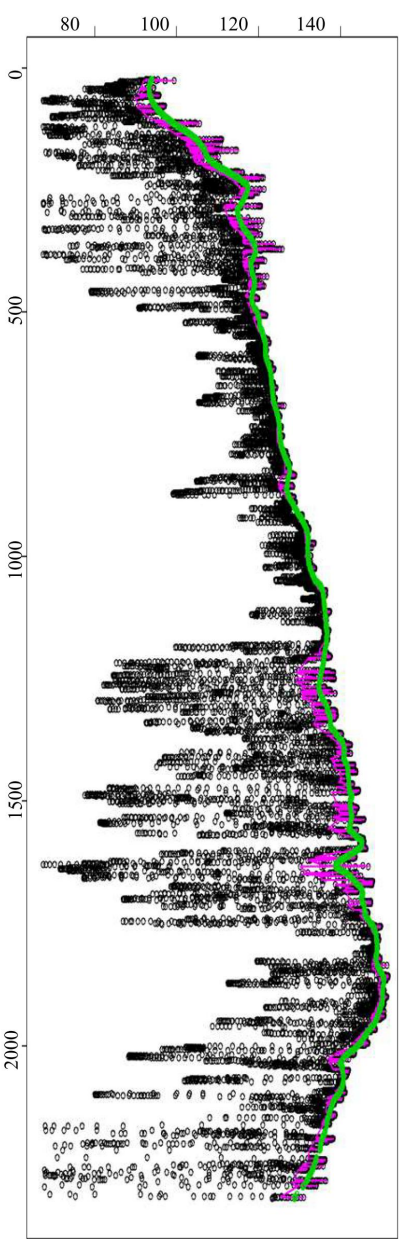

$\mathrm{ni}=2$

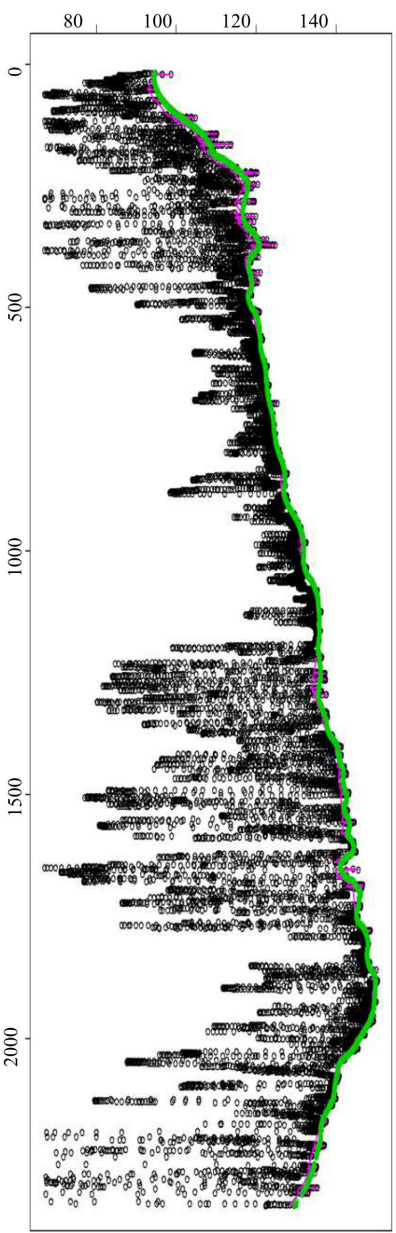

$\mathrm{ni}=3$

Fig. 4. Identification of shale baselines of SP curve (well W0-102. the black scattered points are the raw logging data points, the purple lines are the results of the local polynomial fitting, and the green lines are the baseline values obtained by integrating the fitting results with the original data. Ni equaling 1,2 and 3 represent the number of iterative fittings, respectively. Generally, $\mathrm{Ni}=3$ is believed to have the best results. 

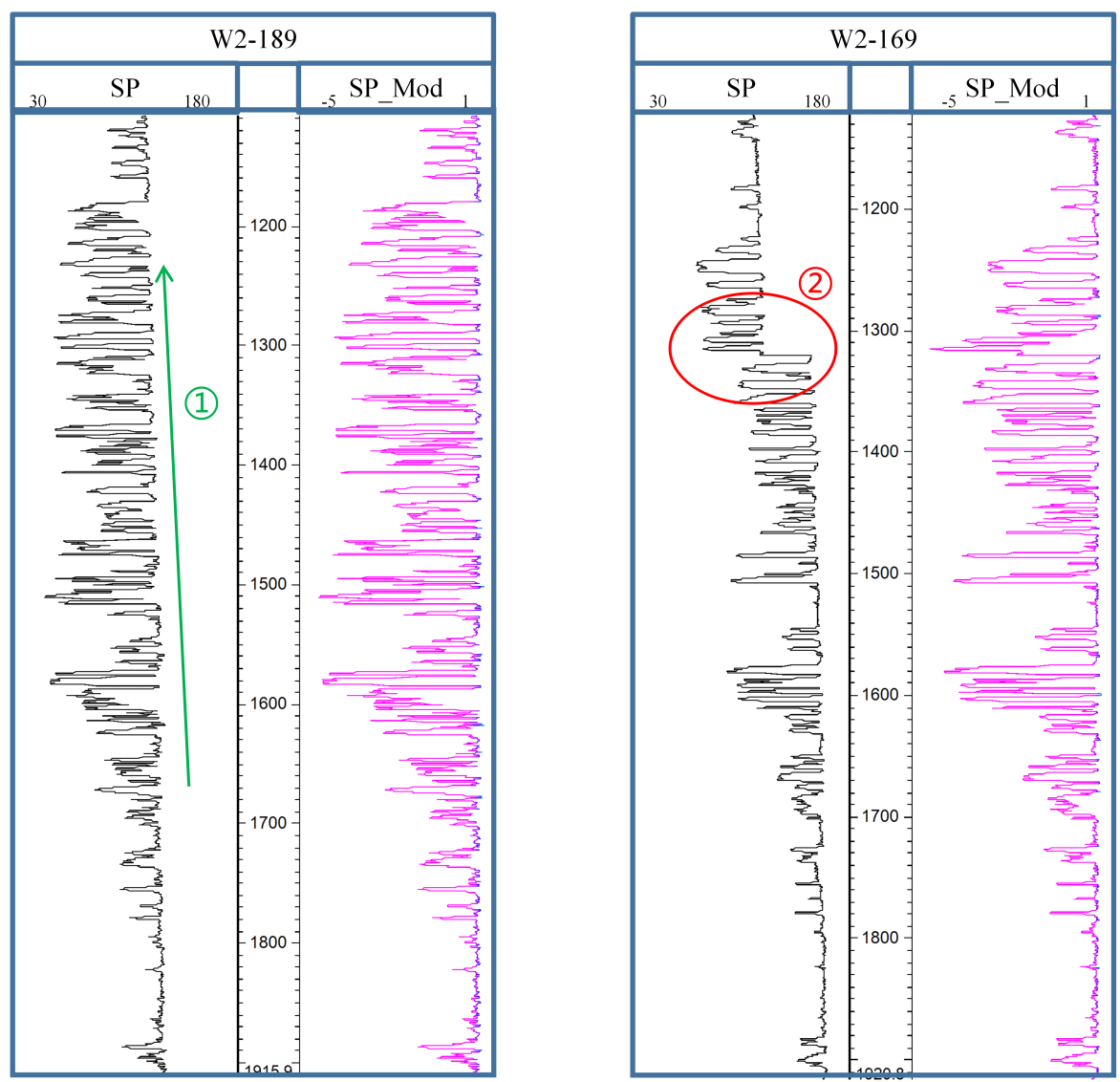

Fig. 5. SP Curve Processing and Optimization (1) Long Cycle Effect Eliminated; (2) Singular Sites Optimized).

and is also the key to accurately identify the sand body. This study starts with identifying the shale baseline of the curve, using a polynomial model to fit the data of the original curve by iteratively approximating the shale baseline of the SP curve (as shown in the green curve in Fig. 4). The corrected data can be obtained by combining the raw data and the shale baseline data. On this basis, the results of the optimization are obtained by unifying the range of values of different wells using statistical properties (Fig. 5).

\subsection{High resolution isochronous stratigraphic correlation}

High-resolution isochronous stratigraphic correlation is an important basis for establishing an accurate reservoir model. The overall mode of the correlation work can be summarized as "man-machine linkage, well-seismic combination". The well-seismic combination means a comprehensive comparison of well $\log$ and seismic interpretation (Fig. 6). Whereas "man-machine linkage" is a combination of manual and the computer-aided system. The computer-aided system used in this study uses some key techniques in the field of image recognition. The manhattan distance (manhattan distance) algorithm compares the similarity of the specific logging curves of the two wells and then determines the location of the counterpart layer based on the optimal offset distance
(Fig. 7). Computer-aided stratigraphic correlation can provide rough corresponding information quickly, and also provide an important basis for subsequent manual participation in detailed correlation.

\subsection{Quasi-magnetic random walk model}

Random walk based reservoir modelling techniques have unique advantages in reservoir architecture characterization and are convenient and efficient in interwell prediction. However, the existing random walk models are often difficult to simulate the ideal result in the area where the well network is irregular and the well distance varies greatly. To solve this problem, the following steps were adopted in this study: (1) By analogy with the principle of magnetic field, a magnetic field model is developed with wells (channel wells) and no channel wells (non-channel wells) as positive and negative magnetic sources; (2) Based on the idea of "repulsion with non-river wells, attracting with river wells and not turning back", a probabilistic random walk model based on magnetic force value is constructed; (3) According to the results of random walk model, the spatial distribution of the channels is optimized by incorporating the information of channel width and width-deep ratio. 

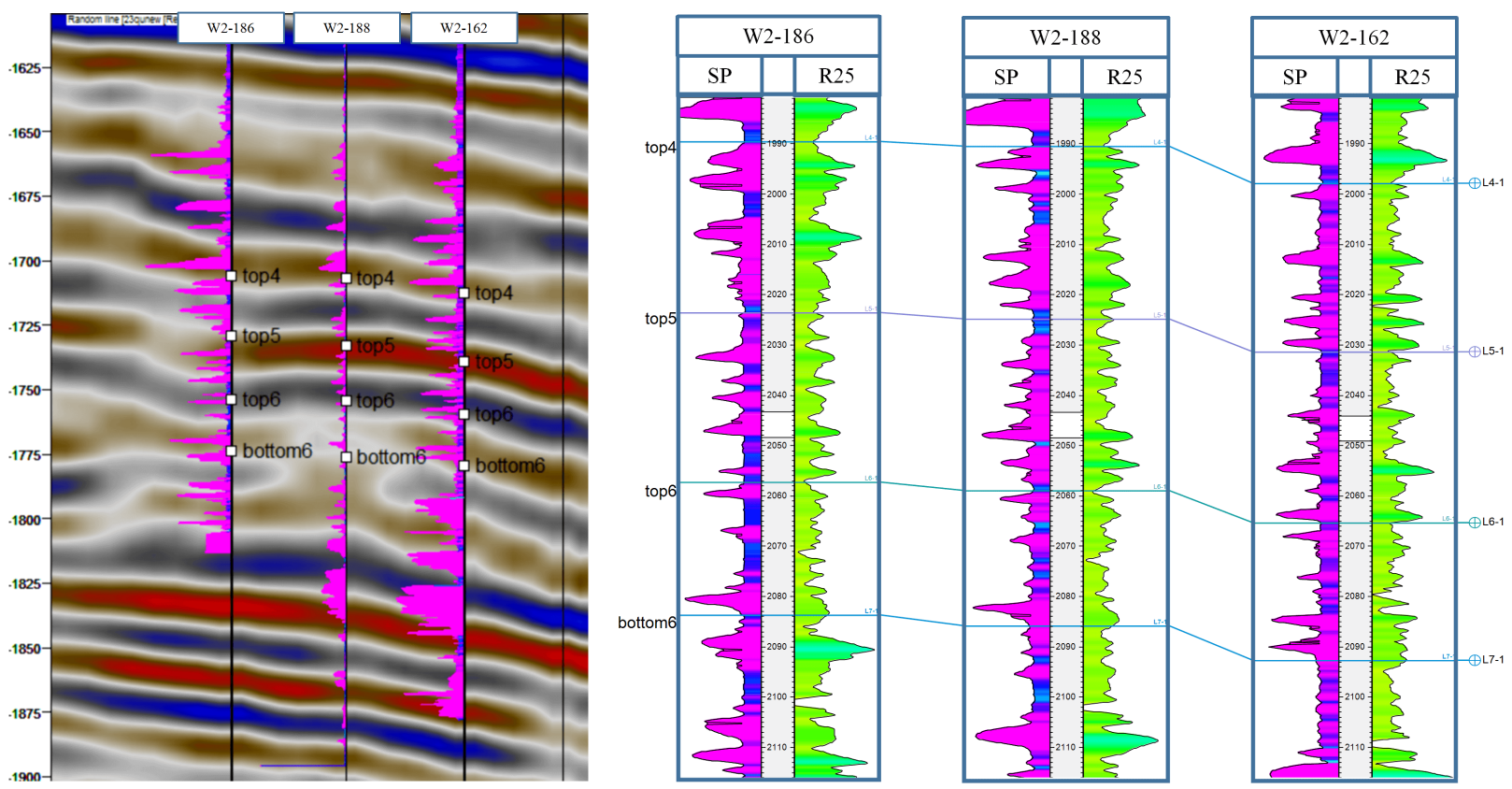

Fig. 6. Well-seismic correlation.

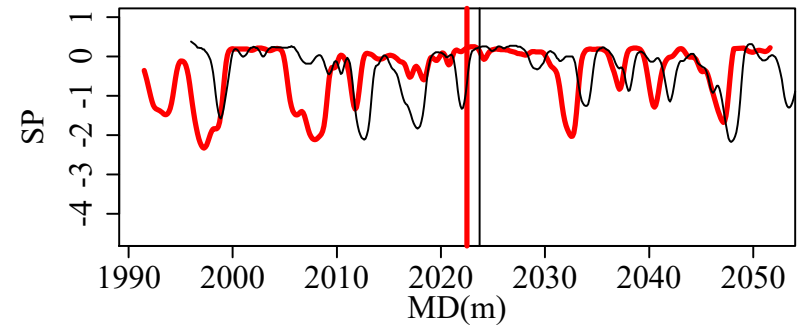

Doing W2-188(black line) based on W2-186 (red line)

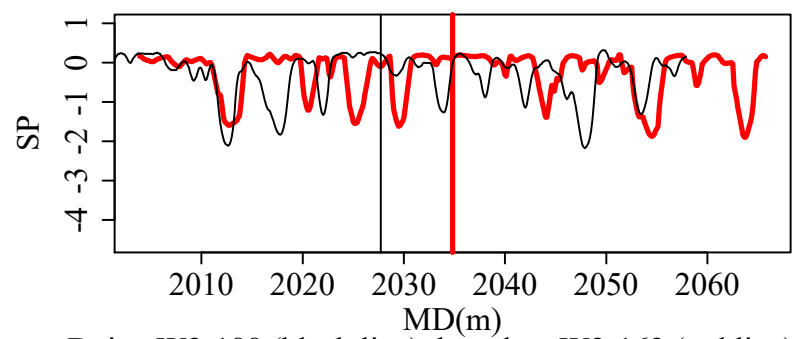

Doing W2-188 (black line) based on W2-162 (red line)

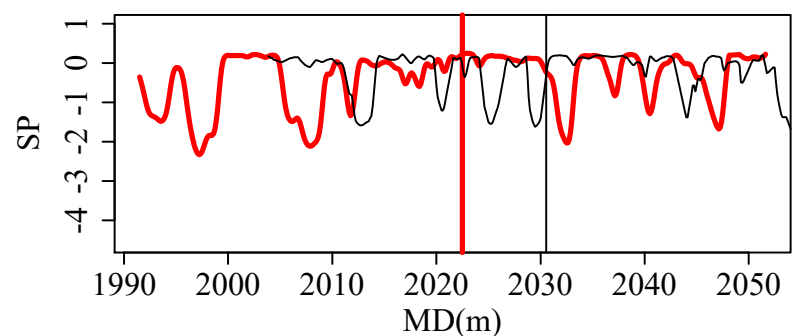

Doing W2-162 (black line) based on W2-186 (red line)
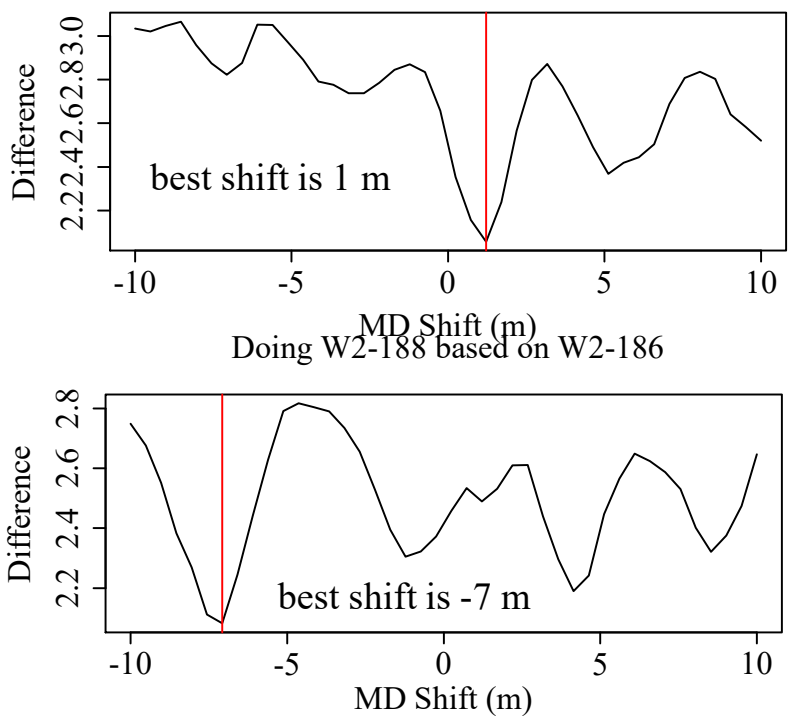

Doing W2-188 based on W2-162

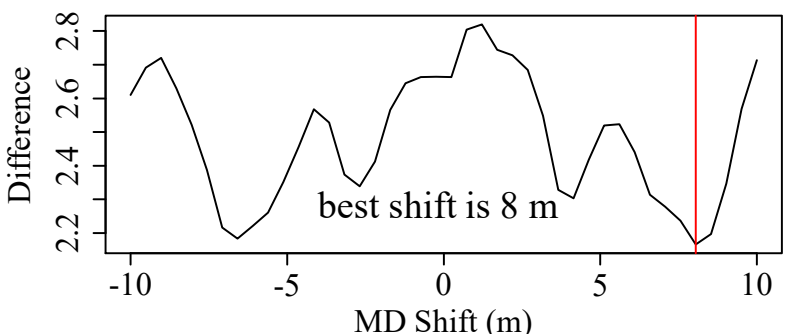

Doing W2-162 based on W2-186

Fig. 7. Computer-aided stratigraphic correlation: Curve similarity calculation and optimal offset distance estimation. 


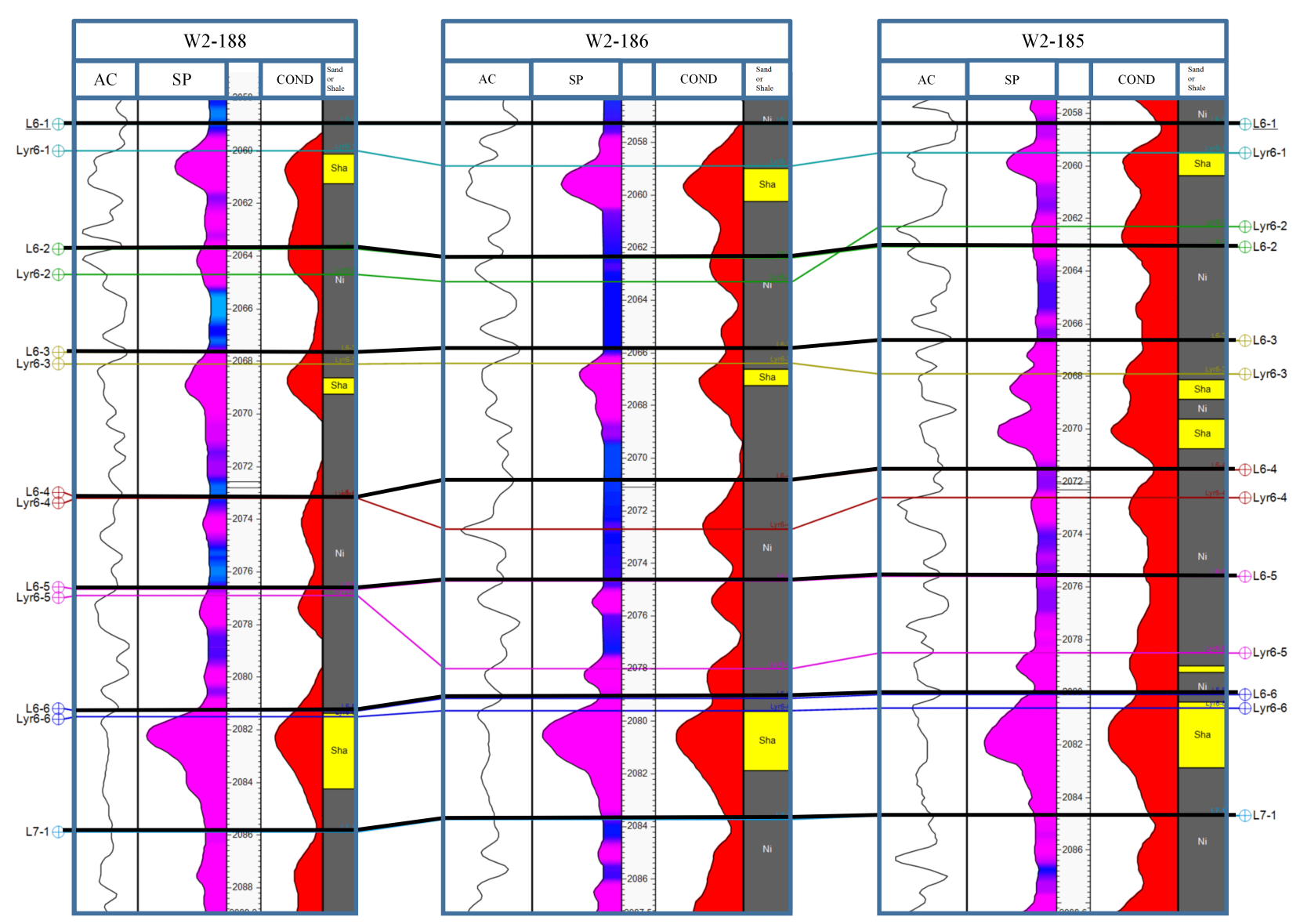

Fig. 8. The contrast between the established stratigraphic framework and the original framework from the oilfield (black lines are the original top boundaries of the small layers; colored lines are the counterparts of this study).

\section{Results}

Compared with the original results from Shengli Oilfield, the isochronous stratigraphic framework has no big difference in the scale of sand group, but there are some differences in the scale of small layer. these differences are mainly reflected in the enhancement of the accuracy of the layer boundary surfaces, split of the superimposed sandbodies and the treatment of the incision of the channels (Fig. 8).

Within the sequence framework, the small layer L6-3 was divided into two periods (L6-3U and L6-3L from top to bottom). The distribution of channel well observations is very irregular in each period. For the L6-3U period, the channel well observations were mainly concentrated in the northwest of the study area, with a small distribution in the middle and less in the south (Figs. 9a and 10a). For the L6-3L period, the distribution pattern is similar to that of L6-3U, but the overall proportion of river well observations is much smaller, and there are almost no channel well observations in the central region (Figs. 9b and 10b). The magnetic cloud maps are consistent with the observation point information of the channel wells that the denser of the channel well observations, the higher value it will be in the could maps (Fig. 9c and 10d). The magnetic walk trajectories and the subsequent river channel distribution maps reflect the main stream direction is NE-SW. Meanwhile, the channel density of L6-3U is considerably larger than that of the underlying L6-3L. Especially, the Northwest part has the highest density of channels, reflecting the characteristics of the superimposed channels (Figs. 9e and 9f; Figs. 10c and 10d).

\section{Discussions}

Accurate identification of shale baselines is an important basis for the follow-up work. In the search for the shale baseline, when the number of iterations $(\mathrm{Ni})$ is too small, the fitting curve cannot reflect the location of the shale baseline (Fig. 4, left $\mathrm{Ni}=1$ ). However, when the number of iterations is too large, the fitting curve becomes the right envelope, which may include some high-frequency noises. Through a large number of experiments and adjustments, 3 is believed to be a good $\mathrm{Ni}$ value that can get relatively appropriate results. The $\mathrm{Ni}$ values here heavily depend on experience and a number of trials. The most suitable Ni value may vary from place to place, which needs a concrete analysis of specific situations.

In this paper, the L6-3 layer is divided into two periods, mainly based on the distance from the top depth of each sandbody to the top surface depth of the corresponding small layer (DST). This paper classified the sandbodies with smaller DST values $(\mathrm{DST}<3 \mathrm{~m})$ into L6-3U period, and the other 

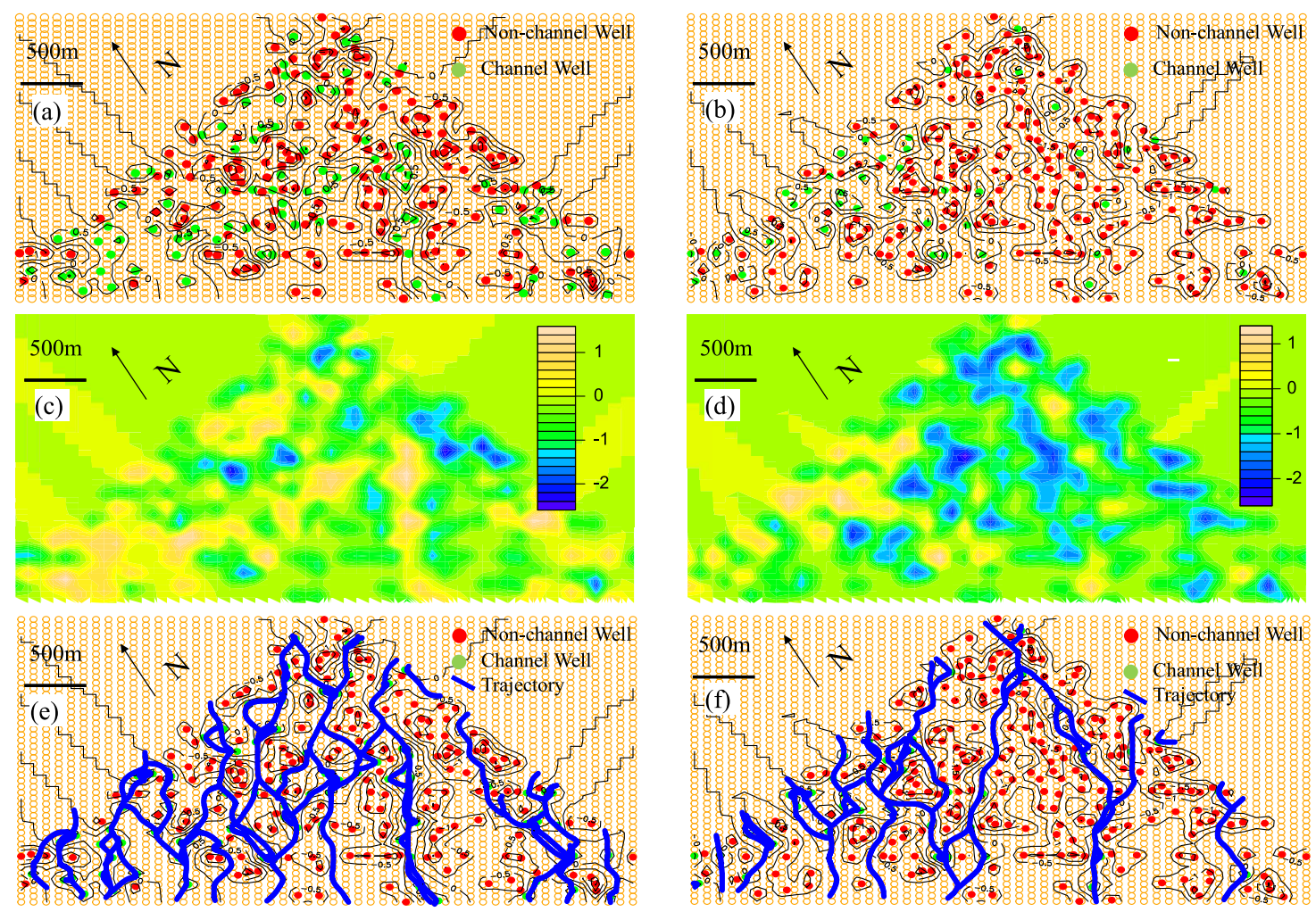

Fig. 9. Quasi-magnetic field and random walk trajectories (a, c: L6-3U magnetic field contour map and magnetic cloud map; a: L6-3L magnetic field contour map and magnetic cloud map; e: L6-3U random walk trajectories; f: L6-3L random walk trajectories)(the source direction is northeast, the original coordinate is rotated counterclockwise $45^{\circ}$ for the convenience of simulation).
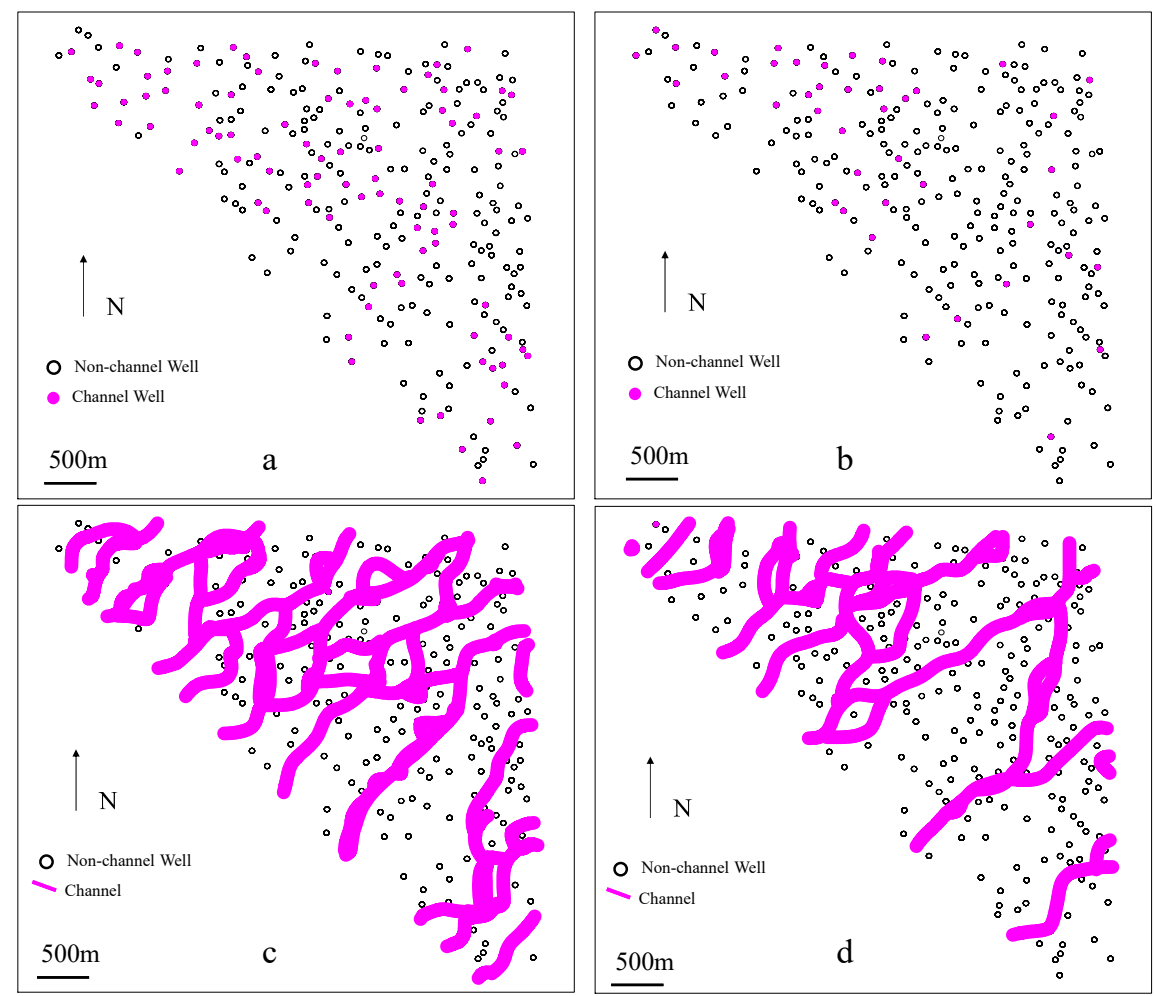

Fig. 10. Well point and simulated channel distribution map (a: L6-3U channel well point distribution; b: L6-3L channel well point distribution; c: L6-3U simulated channel distribution; d: L6-3L simulated channel distribution). 


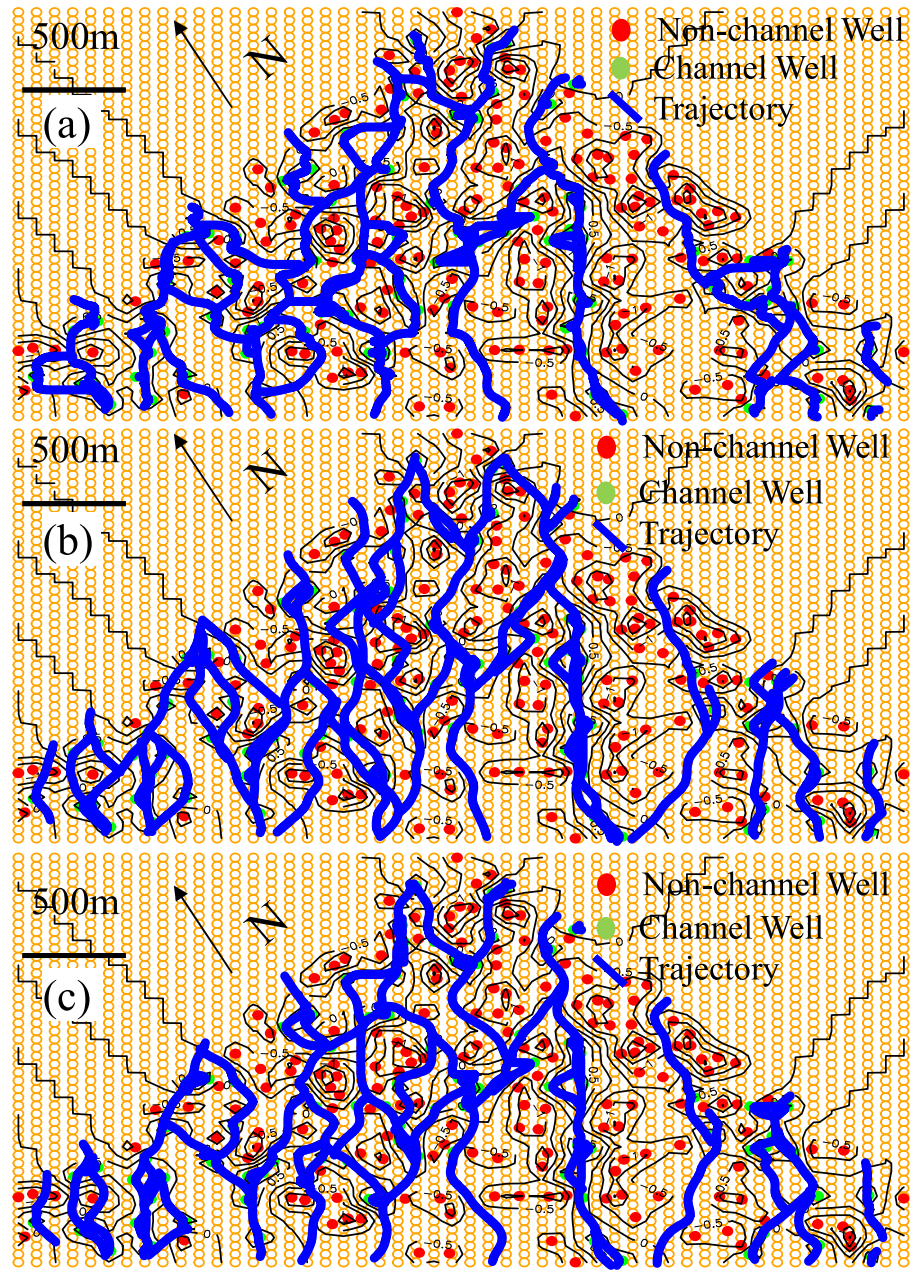

Fig. 11. Comparison of simulation results under different bias coefficients $(B C O)(L 6-3$ upper). a: $B C O=1$, i.e. no bias; $b$ : $B C O=1 / 300$, that is, the probability of the direction perpendicular to the mainstream is artificially reduced by 300 times; $\mathrm{c}$ : $\mathrm{BCO}=0$, that is, the probability of the direction perpendicular to the mainstream is artificially set at $0^{\circ}$.

sandbodies into L6-3L period. In fact, the $3 \mathrm{~m}$ here is a tolerance threshold value. In general, the smaller the tolerance value, the more precise the division is. However, considering the general error of stratigraphic correlation $(1 \sim 2 \mathrm{~m})$, it is meaningless to use too small tolerance.

The number of random walk steps is an important factor in determining the simulation time. The random walk algorithm only limits the maximum number of walk steps, but it is difficult to limit the left-right random swings within the maximum limit. In many cases, the total number of simulated steps can even reach three times the effective number of steps because of this ineffective left-right swings. in this case, much longer simulation time is needed. To overcome this problem, the biased walk probability, i.e., let the simulated probability perpendicular to the mainstream line direction be multiplied by a bias coefficient (DCO) of less than 1 . When DCO is 0 , the simulation will have the fastest speed (Fig. 11c), while with no bias (DCO $=1$, Fig. 11a) the results are quite different. After a large number of simulation attempts, at a DCO of $1 / 300$, the simulation results are best accepted by experienced reservoir geologists, and the simulation time is also saved very much
(Fig. 11b). Therefore, the value of DCO is highly empirical and needs to be fully considered and combined with in-situ experience.

The correction and roughening of the random walk paths resulted in the distribution map of the channels. However, the width of the channels can vary a lot from place to place. Under the current model, the manual adjustment of channel width cannot be completely replaced by computer codes, which is also one of the important directions for future research.

\section{Conclusions}

In this paper, a series of quantitative computer-aided methods are used to realize the detailed architecture anatomy of L6-3 layer of Sandgroup 6 in the second member of Shahejie Formation in District 2, Shengtuo Oilfield. The L6-3 layer can be subdivided into two periods, from top to bottom, L6-3U and L6-3L. The channels of L6-3U period show remarkable NESW direction, which are mainly concentrated in the northwest of the study area, while the channels in central and southern are relatively sparse. The distribution pattern of the L6-3L period is similar to that of L6-3U, but the total number of 
channels is much smaller.

Various quantitative methods used in this paper effectively improve the efficiency of reservoir description and is consistent with the experience of the production geologists. However, it should also be noted that some key parameters used in these models (such as the number of iterations in SP processing and optimization $\mathrm{Ni}$, the tolerance threshold DST in the period division, and the probability bias coefficient DCO in the random walk model) still rely heavily on the experience of field work. In conclusion, the quantitative methods based on well log data for detailed reservoir characterization have great potential for application in fluvial facies, and the reasonable combination of these methods with traditional working experience will provide great assistance for reservoir description.

\section{Acknowledgement}

This study is supported by Initial Fund for Young Scholars of Qingdao University of Science and Technology. Thanks to Prof. Jianchao Cai who has given us many constructive pieces of advice. The authors would also like to appreciate two anonymous reviewers.

\section{Conflict of interest}

The authors declare no competing interest.

Open Access This article, published at Ausasia Science and Technology Press on behalf of the Division of Porous Flow, Hubei Province Society of Rock Mechanics and Engineering, is distributed under the terms and conditions of the Creative Commons Attribution (CC BY-NC-ND) license, which permits unrestricted use, distribution, and reproduction in any medium, provided the original work is properly cited.

\section{References}

Blacknell, C. Morphology and surface sedimentary features of point bars in Welsh gravel-bed rivers. Geol. Mag. 1982, 119(2): 181-192.

Colombera, L., Mountney, N.P., Russell, C.E., et al. Geometry and compartmentalization of fluvial meander-belt reservoirs at the bar-form scale: Quantitative insight from outcrop, modern and subsurface analogues. Mar. Pet. Geol. 2017, 82: 35-55.

Donselaar, M.E., Overeem, I. Connectivity of fluvial point-bar deposits: An example from the Miocene Huesca fluvial fan, Ebro Basin, Spain. AAPG Bull. 2008, 92(9): 11091129.

Ghinassi, M. Chute channels in the Holocene high-sinuosity river deposits of the Firenze plain, Tuscany, Italy. Sedimentology 2011, 58(3): 618-642.

Jiao, Y., Sitian, L. Geologic modeling for outcrop reservoir of continental basin and the conceptual systems. Experimental Petroleum Geology 1998, 20(4): 38-45. (in Chinese)

Kukulski, R.B., Hubbard, S.M., Moslow, T.F., et al. Basinscale stratigraphic architecture of upstream fluvial deposits: Jurassic-Cretaceous foredeep, Alberta Basin, Canada. J. Sediment. Res. 2013, 83(8): 704-722.

Li, J., Liu, S., Zhang, J., et al. Architecture and facies model in a non-marine to shallow-marine setting with continuous base-level rise: An example from the Cretaceous Denglouku Formation in the Changling Depression, Songliao Basin, China. Mar. Pet. Geol. 2015, 68: 381393.

Liang, H., Wu, S., Wa, J., et al. Effects of base-level cycle on mouth bar reservoir micro-heterogeneity: A case study of Es2-9 Formation mouth bar reservoirs in Shengtuo Oilfield. Petroleum Exploration and Development 2013, 40(4): 469-475. (in Chinese)

Lin, B. Shengtuo oilfield fluvial facies reservoir architecturalelements analysis and remaining oil research. Qingdao, China University of Petroleum, 2007. (in Chinese)

Ma, S., Lv, G., Yan, B. Research on three-dimensional heterogeneous model of channel sandbody controlled by architecture. Earth Science Frontiers 2008, 15(1): 5764. (in Chinese)

Miall, A.D. Reservoir heterogeneities in fluvial sandstones: lessons from outcrop studies. AAPG Bull. 1988, 72(6): 682-697.

Nichols, G.J., Fisher, J.A. Processes, facies and architecture of fluvial distributary system deposits. Sediment. Geol. 2007, 195(1-2): 75-90.

Shi, S., Yin, Y., Feng, W. Fluvial facies 3D modeling based on random walk. Complex Hydrocarbon Reservoirs 2011, 4(3): 38-41. (in Chinese)

Shi, S., Yin, Y., Feng, W. The development and prospect of multiple-point geostatistics modeling. Geophysical and Geochemical Exploration 2012, 36(4): 655-660. (in Chinese)

Sun, Z., Lin, C., Dong, C. Boundary distinction mark of the cmplicated meander belt and stacking mode between point-bar sandbodies within the belt. Acta Sedimentologica Sinica 2018, 36(2): 366-375. (in Chinese)

Sun, Z., Lin, C., Du, D., et al. Application of seismic architecture interpretation in enhancing oil recovery in late development Stage-Taking meandering river reservoir in Dongying depression as an example. J. Pet. Sci. Eng. 2020a, 187: 106769.

Sun, Z., Lin, C., Du, D., et al. Quantitative architectural characteristics of deep-lake turbidites: Taking block 146 of Shinan Oilfield in Dongying Depression in China as an example. Mar. Pet. Geol. 2020b, 112: 104046.

Wang, W., Yin, Y. Research progress and trend of reservoir modelling. J. Geol. 2017, 41(1): 97-102.

Willis, B.J. Palaeochannel reconstructions from point bar deposits: A three-dimensional perspective. Sedimentology 1989, 36(5): 757-766.

Willis, B.J., Tang, H. Three-dimensional connectivity of pointbar deposits. J. Sediment. Res. 2010, 80(5): 440-454.

Wu, S., Li, Y. Reservoir modeling: Current situation and development prospect. Marine Origin Petroleum Geology 2007, 12(3): 53-60. (in Chinese)

Xie, Q., Zhu, X., Guan, S., et al. Depositional characterisytics and models of the modern anastomosing river in China. Acta Sedimentologica Sinica 2003, 21(2): 219-227. (in Chinese) 
Yang, T., Cao, Y., Wang, Y., et al. Determining permeability cut-off values for net pay study of a low-permeability clastic reservoir: A case study of the Dongying Sag, eastern China. J. Pet. Sci. Eng. 2019, 178: 262-271.

Yin, Y., Wang, G. A Study on the lateral accretion body type of the meandering river point bar reservoirs. Petroleum Exploration and Development 1998, 25: 37-40. (in Chinese)

Yin, Y., Zhang, C., Shi, S., et al. Modeling on integrating random walk process and multiple-point geostatistics to fluvial reservoirs. Journal of Oil and Gas Technology 2011, 33(8): 44-47+4. (in Chinese)

Yu, X., Li, S., Zhao, S., et al. Constraining method of stochastic modeling for fluvial petroleum reservoir controlled by depositional facies using wells and seismic data. Earth Science Frontiers 2008, 15(4): 33-41. (in Chinese)
Yue, D., Wu, S., Liu, J. An accurate method for anatomizing architecture of subsurface reservoir in point bar of meandering river. Acta Petrolei Sinica 2007, (4): 99103. (in Chinese)

Zhang, C., Xu, L., Lin, K., et al. Anatomy of distributary channel sand, the No. 68 sandbody of youshashan, Western Qinghai. Acta Sedimentologica Sinica 1996, 14(4): 71-77. (in Chinese)

Zheng, L., Chen, C., Lu, C., et al. Study on facies-controlled model of a reservoir in Xijiang 24-3 oilfield in the Northern Pearl River Mouth Basin. Adv. Geo-Energy Res. 2018, 2(3): 282-291.

Zhu, J., Zou, C., Feng, Y., et al. Distribution and controls of petroliferous plays in subtle traps within a Paleogene lacustrine sequence stratigraphic framework, Dongying Depression, Bohai Bay Basin, Eastern China. Pet. Sci. 2020, 17(1): 1-22. 